\title{
THE INFLUENCE OF BED SLOPE CHANGE ON EROSIONAL MORPHOLOGY
}

\author{
Tamaki SUMNER ${ }^{1}$, Takuya INOUE2 ${ }^{2}$ and Yasuyuki SHIMIZU³ \\ ${ }^{1}$ Member of JSCE, Engineer, Suiko Research Co., Ltd. (3-3-2-7, Hiragishi, Toyohira, Sapporo 062-0933, Japan) \\ E-mail: t-sumner@suiko-r.co.jp \\ ${ }^{2}$ Member of JSCE, Researcher, River Eng. Research Team, Civil Eng. Research Inst, for Cold Region \\ (1-3-1-34, Hiragishi, Toyohira, Sapporo 062-8602, Japan) \\ E-mail: inoue-t@ceri.go.jp \\ ${ }^{3}$ Fellow of JSCE, Professor, Graduate School of Engineering, Hokkaido University \\ (North 13, West 8, Kita, Sapporo 060-8628, Japan) \\ E-mail: yasu@eng.hokudai.ac.jp
}

\begin{abstract}
New waterway projects such as cutoffs and gravel extractions have been carried out all over the country. The shortcuts have lowered river water surface elevation during flooding, and they have been shown to suppress these flooding events. On the other hand, the riverbed elevations rapidly decreased as bed slope changed artificially and canyons were formed in several rivers. Little is known about how riverbed degradation occurs or how the canyon is formed by change in the bed slope. In this study, we conducted numerical simulations to evaluate the deformations of alluvial bed and peat bed. The results suggest that the bed slope becomes constant on the alluvial bed and the erosion proceeds at the bare peat bed. The results also show that the upstream migration of the peat bed slope forms cyclic steps morphology. Also, we carried out numerical simulation to reproduce bed degradation of the Yubari River caused by cutoffs.
\end{abstract}

Key Words : new waterway project, erosional morphology, numerical simulation, cyclic step, peat layer

\section{INTRODUCTION}

River improvement works, such as shortcut constructions (cut-off channels), new waterway projects, and gravel extractions have been conducted all over the country. Especially, shortcut constructions of rivers have the effect of improving the discharge capacity during floods and reducing the flooding, which contribute greatly to easing our lives today. On the other hand, although the original riverbed slope is changed by the river improvement, the riverbed may degrade rapidly. For example, downstream of the Yubari River ${ }^{1}$, a canyon resembling Niagara Falls (Fig. 1) appeared, requiring the installation of ground sills as countermeasures (Fig. 2).

Machida $^{2)}$ stated that man-induced changes in rivers impact the fluvial geomorphic system and the sediments try to achieve an equilibrium in the upstream and downstream sides of the river. Besides, as a characteristic phenomenon at the slope changing point, it has been confirmed that coarse sediment accumulates at the upstream of the change point ${ }^{3)}$. The impact of shortcuts on rivers has already been studied, such as the habitat prediction of the river environment after shortcut in the Satetsu River ${ }^{4}$, numerical calculation of flow and deformation of river bed at the ground sill installation ${ }^{5), 6)}$, etc.

The river bed at the downstream of the Yubari River where the canyon appeared, is composed of peat mostly. The previous studies on river bed configuration analysis dealt with the cases of alluvial bed, but hardly explored the changes in the peat bed. According to the Geotechnical Terms Glossary ${ }^{7}$,

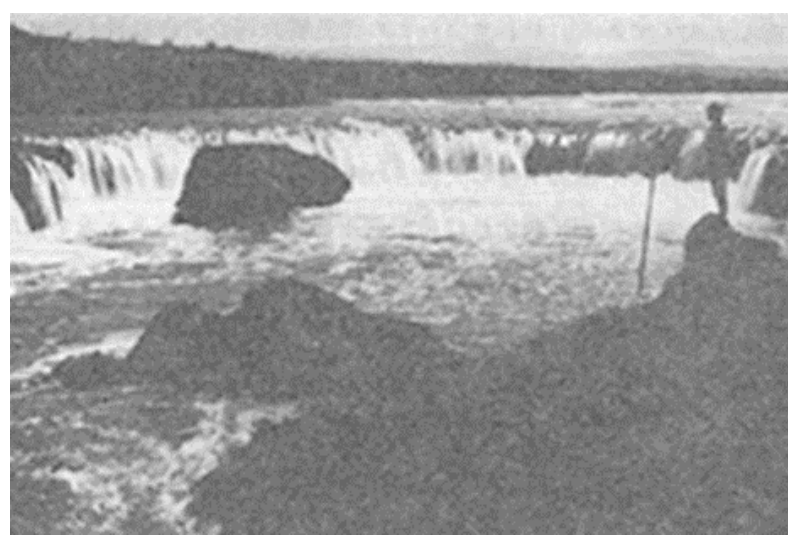

Fig. 1 Canyon at the new waterway (From History of Ishikari River). 


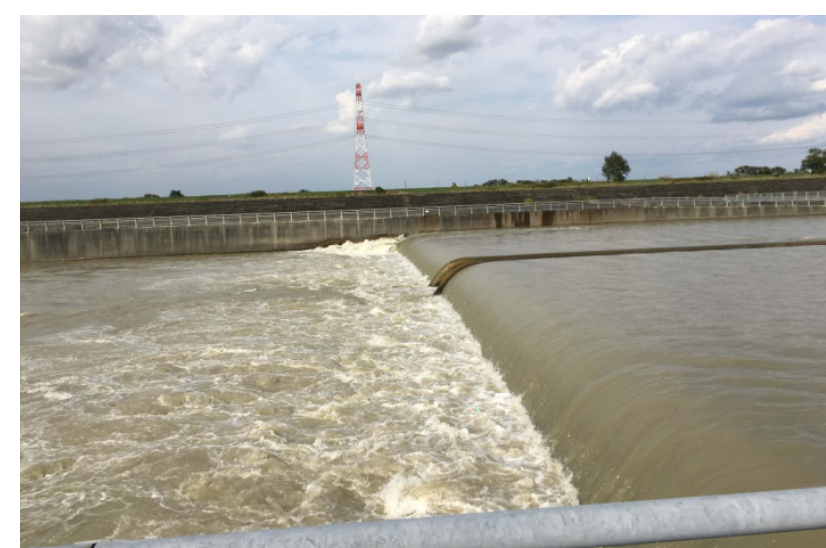

Fig. 2 Kiyohoro Groundsill in September 2016.

soil containing $50 \%$ or more of organic components are generally called high organic soil, while decomposed and fibrous soil is classified as peat. Ninety percent of peatlands are distributed in cold regions of the northern hemisphere, and focusing on Japan, most of them are distributed in Hokkaido. In the Peaty Soft Ground Countermeasure Manual ${ }^{8}$, peat has a higher water content ratio, a higher void ratio, and a higher compressibility compared to soft clay. On the right bank of KP6.5 in Yubari River, we confirmed that the peat consisted of organic substance and soft fluffy soil mixed with adhesive materials (Fig. 3). KP stands for the distance $(\mathrm{km})$ from the confluence point of main stream.

In this study, numerical simulations were conducted to elucidate two questions: how the riverbed deformation process of the peat bed differed from the alluvial bed, and how the canyon was formed and migrated upstream. Also, we investigated if the model can reproduce the peat bed erosional morphology that occurred in Yubari River after the river shortcut construction.

\section{METHOD OF NUMERICAL SIMULA- TION}

\section{(1) Erosional rate of the peat bed}

We adopted the calculation of unsteady two-dimensional plane flow similar to the solver Nays $2 \mathrm{DH}$ of iRIC software (http://i-ric.org/en/software/18/) for the numerical simulation model of this study. Explanations of basic formulas of the flow and the bed deformation method of the alluvial bed are described on the Nays2DH home page, but only the part related to the river bed deformation method of the peat bed is described in this paper. In addition, for the continuous equation of sediment, the method of the numerical calculation of Inoue et al..$^{9}$ is used.

In this study, we assumed that the erosion would occur even with a small flow velocity on the peat bed, and it was speculated if the prediction formula of

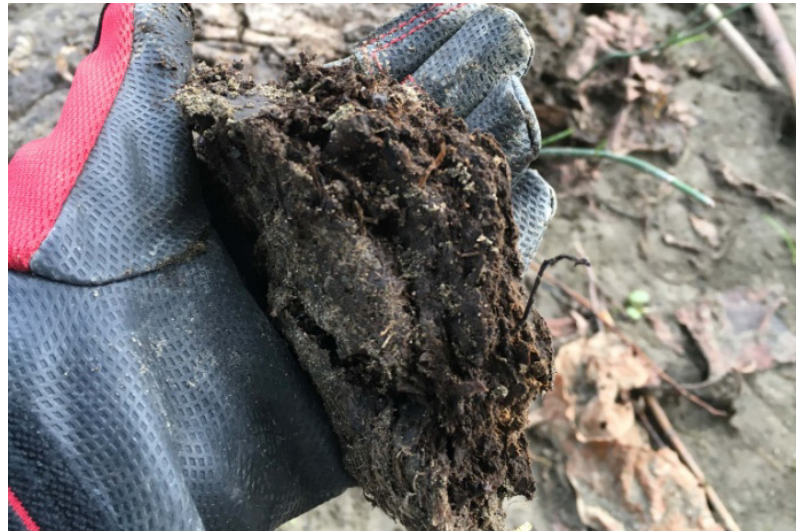

Fig. 3 Peat in the Yubari River.

erosion dependent on shear velocity, proposed by Nishimori and Sekine ${ }^{10}$, could be applied. Sekine et al. has confirmed that the erosion rate of the cohesive soil bed depends on the cube of the friction speed, the water temperature, and the water content of 2.5 th power, applied to the peat bed as follows:

$$
\begin{gathered}
E_{p}=\Theta u^{* 3} \\
\Theta=\alpha(T) R_{w c}^{2.5}
\end{gathered}
$$

where $E_{p}$ denotes the erosion rate of the cohesive soil converted to peat bed; $\Theta$ denotes a coefficient that depends on the type of clay mineral, water temperature, etc.; $u^{*}$ represents the shear velocity; $\alpha$ is a coefficient of water temperature; $T$ stands for water temperature; and $R_{w c}$ denotes the water content.

Sekine et al. stated that the surface of the cohesive soil is not always smooth, waves on river bed may be formed, and sediment transported as bedload may be deposited in the recesses. Therefore, assuming that the erosion rate of the peat bed was influenced by the alluvial cover rate, the following equation was developed:

$$
\frac{\partial \eta_{p}}{\partial t}=-\Theta u^{* 3}\left(1-P_{c}\right)
$$

where $t$ denotes time; $\eta_{p}$ denotes the elevation of the peat bed; and $P_{c}$ denotes the alluvial cover rate. The alluvial cover rate is expressed using the ratio of the macroscopic roughness height of the peat bed $L$ to the alluvial thickness $\eta_{a}{ }^{11)}$ :

$$
P_{c}=\left\{\begin{array}{cl}
\eta_{a} / L & \text { for } 0 \leq \eta_{a}<L \\
1 & \text { for } \eta_{a} \geq L
\end{array}\right\}
$$

According to the study of Sekine et al., the height of the surface roughness corresponds to three to seven times the grain size. Therefore, in this study, $L$ was set to three times the grain size ${ }^{10)}$. 


\section{(2) Total height of the riverbed deformation}

Total height of the riverbed deformation $\eta$ was calculated using the following formula, which combined the variation in the alluvial thickness and the erosion of the peat bed:

$$
\frac{\partial \eta}{\partial t}=\frac{\partial \eta_{a}}{\partial t}+\frac{\partial \eta_{p}}{\partial t}
$$

\section{COMPARISON BETWEEN ALLUVIAL BED AND PEAT BED}

\section{(1) Numerical conditions}

In order to elucidate the longitudinal erosion process, the numerical experiments were conducted under narrow river width conditions. Figure 4 shows the longitudinal profile of the initial riverbed of numerical experiments. A channel shape was set to a rectangular cross-section. The flume had a length of $30 \mathrm{~m}$, width of $0.1 \mathrm{~m}$, bed slope of $1 / 300$ in the upstream for $10 \mathrm{~m}$ and $10 \mathrm{~m}$ of downstream, and bed slope of $1 / 50$ in the middle, which was assumed to be the section of cut-off. The grid size was set to $0.1 \mathrm{~m} \times 0.1 \mathrm{~m}$. The upstream and downstream ends were extended by $10 \mathrm{~m}$ each as an approach section. Sediment grain size of $0.77 \mathrm{~mm}$ was employed, the water discharge per unit was $0.0125 \mathrm{~m}^{2} / \mathrm{s}$, and Manning's roughness coefficient was 0.012 .

In the study of Sekine et al. ${ }^{12)}$, the flume experiments showed that the value of coefficient $\Theta$ was from $0.78 \times 10^{-5}$ to $3.89 \times 10^{-5}$ when $R_{w c}=1$. In this study, $\Theta$ was set to a larger value of 0.5 to save on calculation time. However, we confirmed that the same topography was formed between 0.005 and 0.5 for the value of $\Theta$. The values of water temperature and water content could be constant as we wanted to compare the peat bed and alluvial bed. We also assumed that the peat bed had a more significant influence on friction velocity than the cohesive bed. The validity of the value of $\Theta$ is an issue to be concerned about in the future. The dimensionless critical shear stress of the alluvial bed calculated from Iwagaki's formula $^{13)}$ is 0.034 and the dimensionless critical shear stress of the peat bed adapted to Inoue's equation, ${ }^{14), 15)}$ which changes with riverbed roughness is 0.025 .

Table 1 shows the numerical conditions of the experiments. The type of riverbed was calculated using case1_a for the alluvial bed and case1_p for the peat bed. The sediment feed rate was discharged at $5.71 \times 10^{-6} \mathrm{~m}^{2} / \mathrm{s}$, which was the equilibrium of the sediment transport rate per unit of the upstream end condition where the bed slope was $1 / 300$ for both case $1 \_$a and case $1 \_$p, and the calculations for 100 hours were performed.

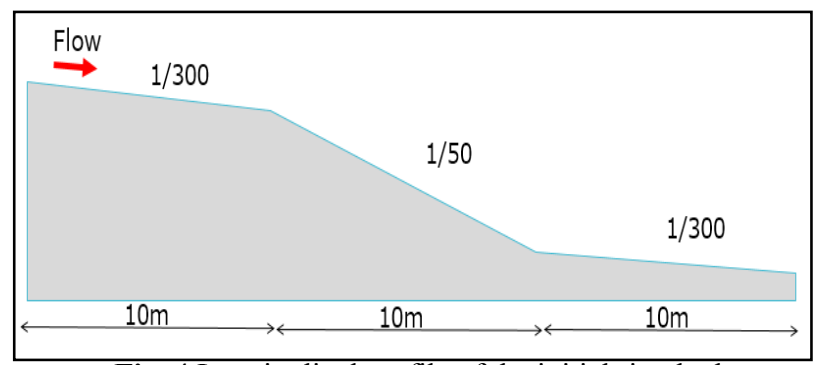

Fig. 4 Longitudinal profile of the initial riverbed.

Table 1 Numerical conditions of case1.

\begin{tabular}{|c|c|c|}
\hline Case & Type of bed & $\begin{array}{c}\text { Sediment feed rate } \\
\text { per unit }\left(\mathrm{m}^{2} / \mathrm{s}\right)\end{array}$ \\
\hline \hline case1_a & Alluvial bed & $5.71 \times 10^{-6}$ \\
\hline case1_p & Peat bed & $5.71 \times 10^{-6}$ \\
\hline
\end{tabular}

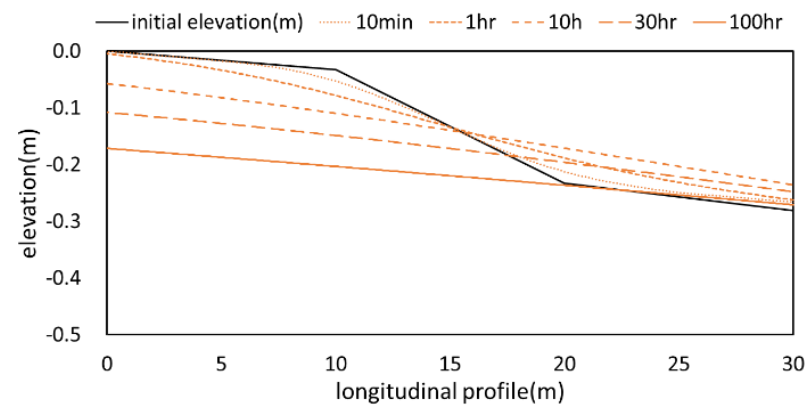

Fig. 5 Height of riverbed deformation by alluvial bed (case1_a).

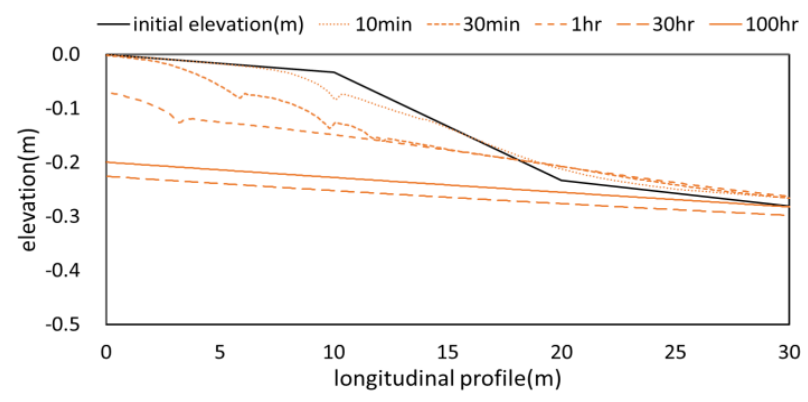

Fig. 6 Height of riverbed deformation by peat bed (case1_p).

\section{(2) Calculation results}

Figures 5 and 6 show the calculation results of case1_a and case1_p, respectively. In the results, the bed slopes eventually became constant, and the river bed degradation remarkably occurred in all cases. Comparing the calculation results of case1_a and case1_p, the final riverbed slopes approached the equilibrium state of slope $1 / 300$; however, riverbed degradation processes were different. The alluvial bed became constant from the early stage, and the slope shifted to $1 / 302$ towards the end of the experiment. Meanwhile, in the case of peat bed of case1_p, the erosion occurred from a transition point from the sub-critical flow to super-critical flow by slope 


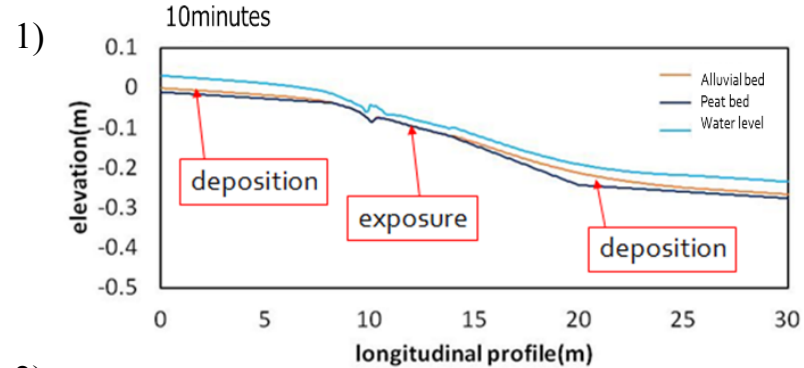

2)

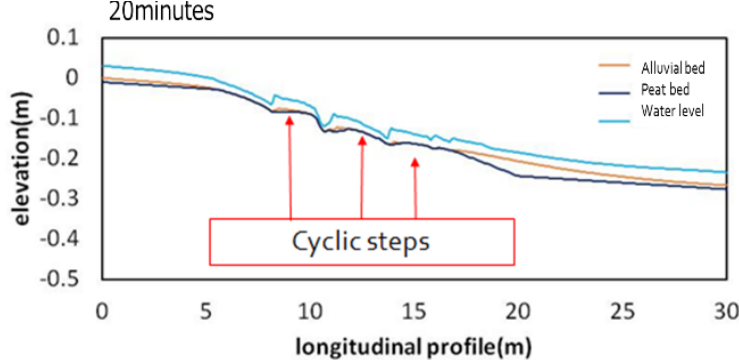

3)

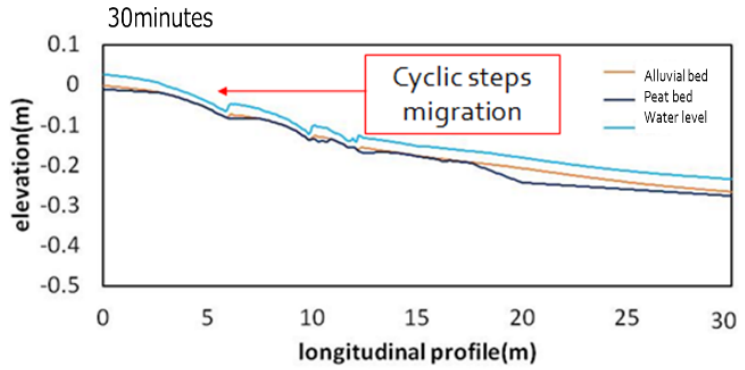

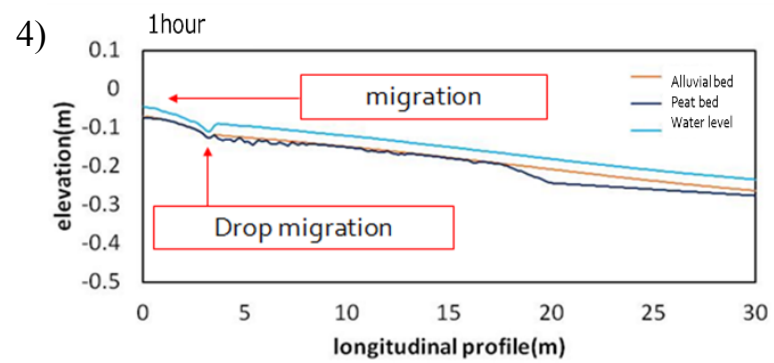

5)

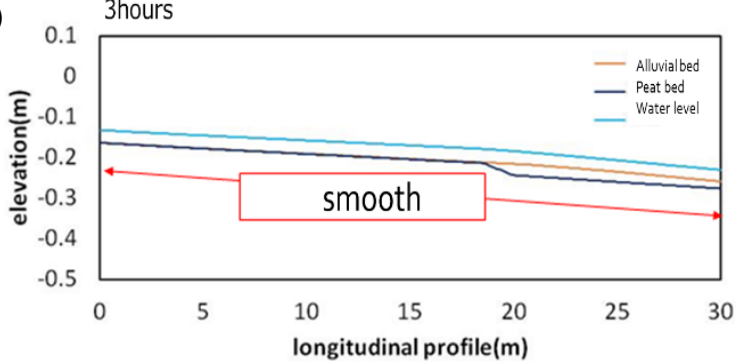

6)

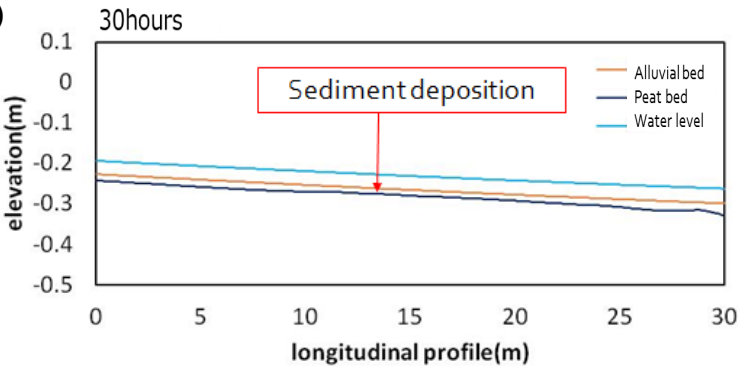

Fig. 7 Process of canyon formation by calculation.

change on the upstream side of the middle section. The incision progressed and formation of a cyclic step topography occurred. This step topography repeatedly eroded while moving towards the upstream side with the lapse of time, and finally the riverbed became constant due to bed degradation in all sections. Once the degradation happened, after 30 hours the bed slope became $1 / 384$, which was milder than $1 / 300$. As sediment gradually accumulated and approached the equilibrium, the slope was $1 / 357$ in 100 hours.

\section{(3) Erosional morphology in the riverbed with slope change}

As a result of case $1 \_$, a formation process of erosional morphology in the riverbed with slope change is assumed as follows (Fig. 7): 1) First, sediment deposits on the river bed where the slope is mild, and the peat bed is exposed where the slope is steep. Erosion occurs at places where the flow velocity is large in the erosion exposed section. 2) Due to the erosion of the river bed, the flow velocity is distributed in the flow direction. The flow transits continuously from sub-critical flow to super-critical flow and from super-critical flow to sub-critical flow to form the steps topography, and it creates a waterfall. Parker and Izumi ${ }^{16)}$ confirmed in the theoretical analysis of the step topography of cohesive soil that cyclic step formation occurs in steep rivers. Calculation result shows that cyclic step topography is formed in steep slope, which is in agreement with the theoretical analysis. 3) As Parker and Izumi stated, it was also observed that cyclic steps migrated upstream while eroding. The bed slope gradually becomes mild, and the flow velocity slows down as the vertical erosion progresses to deposit layer of sediment. Therefore, the sediment begins to deposit on the peat bed. 4) By repeating the upstream migration of transition to alluvial bed, the height of the river bed drops increase. 5) This is because the difference between the slope of the alluvial bed shifts and the initial bed height increases toward the upstream. The bed slope eventually becomes constant owing to sediment deposition. 6) Finally, the river bed reaches a state of equilibrium to the sediment feed rate. The slope of erodible bed can be changed to constant or dynamic equilibrium state because the slope attempts to sustain equilibrium corresponding to the sediment feed rate by feeding a constant amount of sediment. This calculation result suggests that the peat bed is different from the alluvial bed in terms of the process of river bed degradation. However, eventually both have a constant slope and approach the same eroded landform. 


\section{REPRODUCTION OF RIVERBED DEG- RADATION AT THE DOWNSTREAM OF YUBARI RIVER}

\section{(1) Overview of the Yubari River}

The Yubari River is a tributary of the Ishikari River located in the central area of Hokkaido. The low-lying area in the downstream part of the Yubari River, which was the subject of this study, was a soft land with a wetland spreading along the peat distribution area in the early Meiji period. Moreover, it was placed in an unstable and wet environment where inundation occurred every year due to snow melt runoff and floods. As a countermeasure to prevent flooding in the low-lying area, the Yubari River New Channel Project, which directly switched the Yubari River (which had merged with the Chitose River to the Ishikari River), was completed in 1951. In spite of the passage of water, one year later, a scouring like Niagara Falls of $4 \mathrm{~m}$ in height near KP2.2 appeared. The scouring migrated upstream at a speed of $5-7 \mathrm{~m}$ per day. In the new waterway project, a groundsill was installed at KP8 for the agricultural siphon and scouring prevention of the Kiyohoro Bridge. Therefore, a second groundsill was installed downstream from the first due to the unexpected scouring. The river channel implemented at the slope of $1 / 1200$ gently became $1 / 4000$, and the height of the drop was larger at the second groundsill, the Kiyohoro Groundsill.
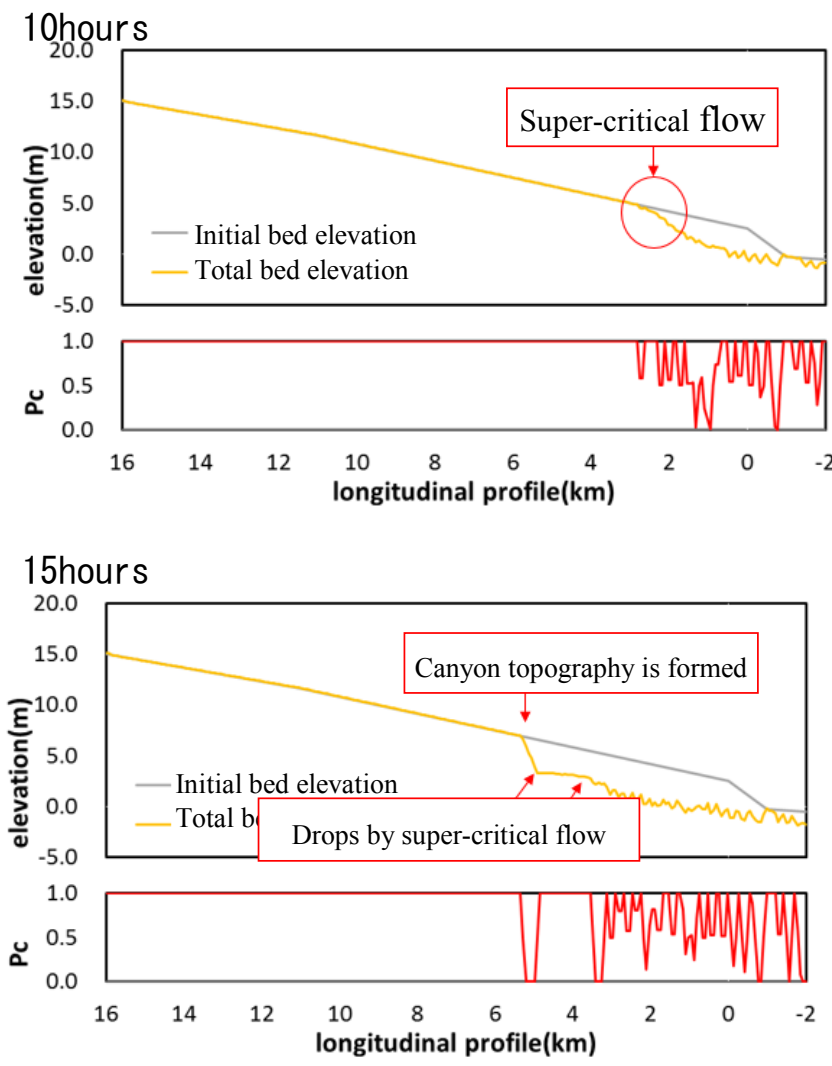

\section{(2) Numerical conditions}

Calculation was performed to reproduce the change in bed slope of Yubari River due to the construction of a new waterway section (KP2 to KP16 of the Kurisawa Weir) at the confluence of Ishikari

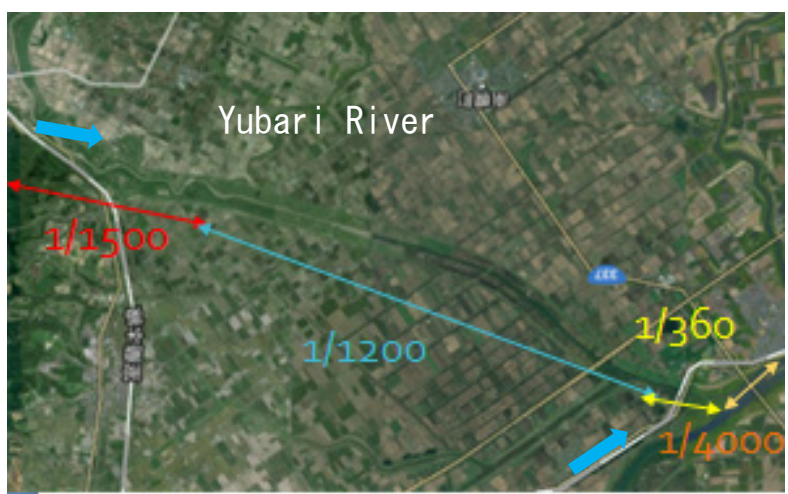

Fig. 8 Yubari River (Google Map).

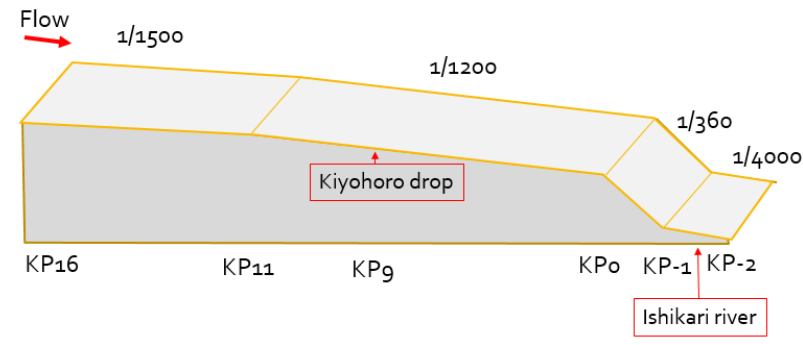

Fig. 9 Initial bed slope of the Yubari River.
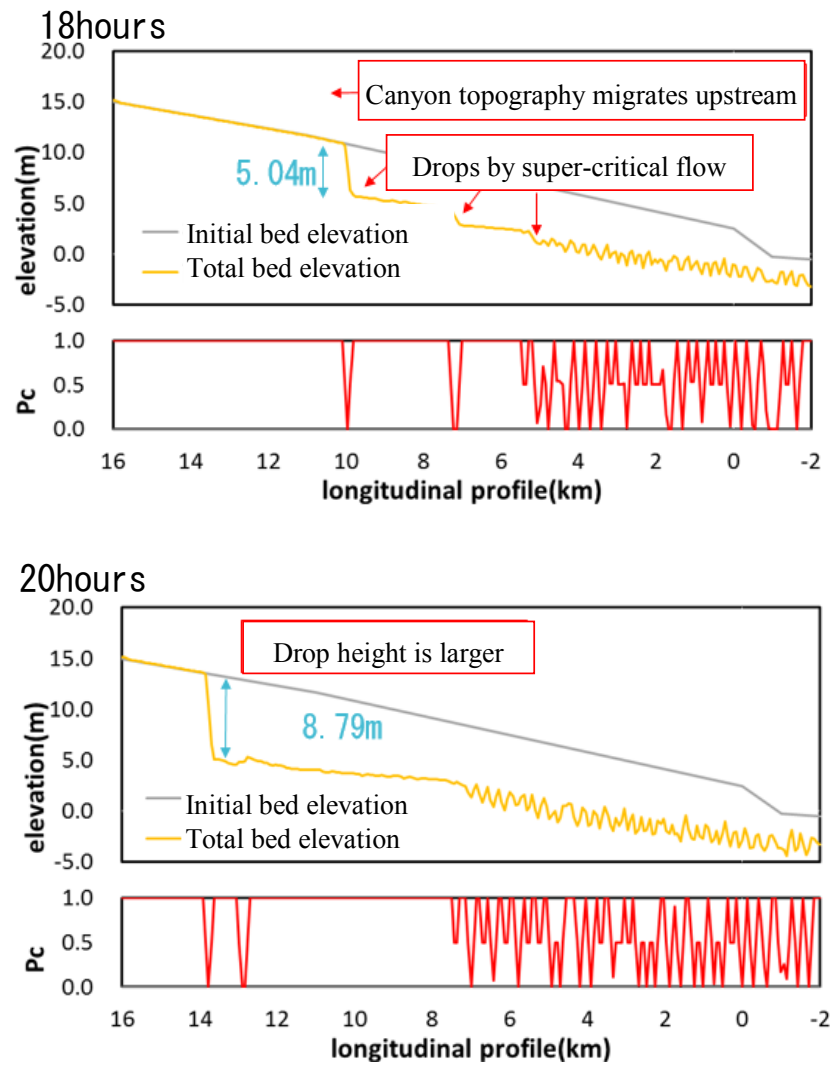

Fig. 10 Longitudinal profile of riverbed elevation and alluvial cover rate. 


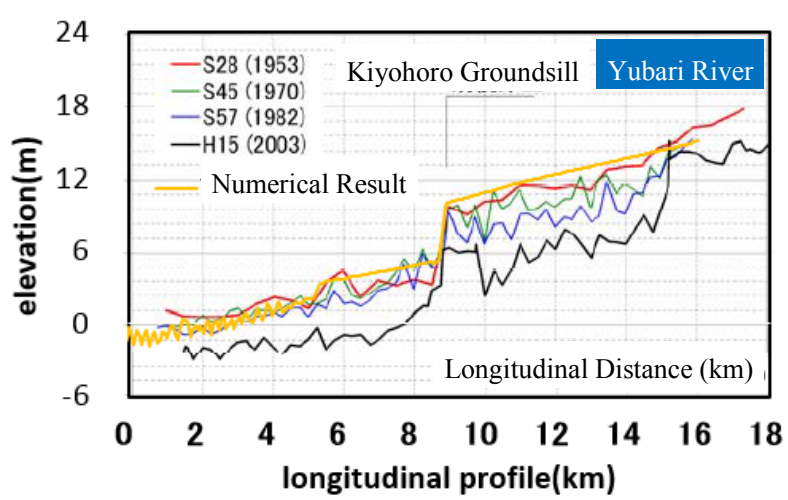

Fig. 11 Comparison of mean riverbed elevation of measured and calculation results.

River (Fig. 8.) The calculation model adopted the erosion rate formula of the peat bed used in case1_p. Coefficient depended on the type of clay mineral, and water temperature was set to 0.5 as in case 1 _ p performed in previous experiments. The numerical flume has a width of $72 \mathrm{~m}$ according to the plan specifications of the Yubari River Shortcut Construction ${ }^{1)}$ and total length of $18 \mathrm{~km}$. One grid size is $100 \mathrm{~m} \times 72 \mathrm{~m}$. The riverbed slopes of the waterway are set as 1/1200 from KP0 to KP11, 1/1500 from KP11 to KP16, 1/360 from the confluence point of the Ishikari River KP-1 to KP0, and 1/4000 from the main stream of Ishikari River KP-2 to KP-1 (Fig. 9), which is in accordance with the bed elevation data obtained at the time of installation of the new waterway.

From 1973 to $2014,40 \mathrm{~m}^{3} / \mathrm{s}$ of average annual water discharge was noted, producing sediment of $2.67 \times$ $10^{-4} \mathrm{~m}^{2} / \mathrm{s}$, which was an equilibrium sediment transport rate per unit with a slope of $1 / 1200$. The uniform sediment grain of $1 \mathrm{~mm}$ from the river bed material sieving test table (1964) and Manning's roughness coefficient of 0.025 were applied.

\section{(3) Results and discussion}

Figure 10 shows the calculation results of riverbed height and the alluvial cover rate $P_{c}$ after 10 hours from the start of the calculation. After the exposure and erosion of the peat bed near KP0, the step-like topography was observed in the section of the transition of super-critical flow to sub-critical flow (10 hours). The graph of $P_{c}$ shows that the place the sediment deposited and the place the peat bed exposed are mixed in the downstream section of KP3 eroding the peat bed. After 15 hours, a drop formed by the super-critical flow gradually became larger, and a canyon-like topography of $3.64 \mathrm{~m}$ in height was formed near KP5.3. The bed in the upstream of the canyon near KP5.3 was not eroded and flat because of sediment deposition. After 18 hours, the canyon headed to KP10 and the drop height became $5.04 \mathrm{~m}$.
The drop height increased to $8.79 \mathrm{~m}$ at KP13.84 after 20 hours. As a result, the migrating speed of the canyon was accelerated to $1.59 \mathrm{~km} / \mathrm{h}$ in 18 hours, and $1.94 \mathrm{~km} / \mathrm{h}$ in 20 hours. The characteristics of the river bed deformation, such as the increased canyon's drop as it migrated upstream, was represented by the numerical calculation.

There is no record of river bed elevation of the canyon formation time in the Yubari River (in 1937). Therefore, we compared the measured average bed elevation from 1953 to $2003^{17)}$ and the average bed elevation of the calculation result when the canyon reached the Kiyohoro Groundsill (Fig. 11). Compared with the oldest average bed elevation in 1953, the results of calculation show that the elevation was $1 \mathrm{~m}$ higher than the measurement between KP6.5 and downstream of the Kiyohoro Groundsill. However, the results suggest that we could reproduce the deformation caused by canyon formation occurring due to the erosion at downstream and migration to upstream, which was characteristic of river bed degradation at downstream of the Yubari River. Moreover, unlike the peat bed calculation result (case1_p) described above, the canyon topography migrated upstream rather than the step topography forming eroded morphology. It can be inferred that the river bed slope at downstream of the Yubari River was mild and the flow was unlike the condition the cyclic steps formed. In this numerical calculation, the coefficient depending on the type of clay mineral and water temperature and the parameters of water discharge were given values from inference, and adequate consideration is needed for validation.

\section{SUMMARY}

The findings obtained in this study are as follows:

1) We carried out numerical simulations to understand the difference in the bed deformation process between the alluvial bed and the peat bed when river bed slope changes. As a result, in the case of the alluvial bed, the slope smoothed and became constant from the beginning of the calculation to maintain the balance of the bed. Conversely, in the case of the peat bed, the river bed was balanced by the sediment and tended to approach a constant slope similar to the alluvial bed; however, the process of bed deformation was different. We observed that the peat bed topography like cyclic steps due to the influence of the friction velocity. The topography also formed an erosional morphology with the drop as it migrated upstream.

2) We carried out a numerical simulation of the deformation in the Yubari River leading to the 
formation of a canyon, by using the erosion model of the peat bed. As a result, the erosion caused by super-critical flow at the point of bed slope changed near the confluence of Ishikari River. Furthermore, the erosional morphology migrated upstream with gradual acceleration and became a canyon with a large drop in height. The erosional morphology indicates that the degradation process caused by the construction of a shortcut of downstream of the Yubari River can be reproduced roughly. However, the lack of elevation data and water discharge data from the time of formation of canyon in 1937 must be considered. Validating various conditions such as the coefficient depending on the type of clay minerals and water temperature is also important.

\section{REFERENCES}

1) Yamaguchi, H., Shinagawa, M. and Seki, H.: Cutoffs, Hokkaido River Disaster Prevention Research Center, 1996.

2) Machida, $T$.: Response of fluvial system to human impact on riverbed forms and material in the Mid-Arakawa, Central Japan: A preliminary discussion, Global Environment Engineering Research, Vol. 15, pp. 17-27, 2013.

3) Aoki, T. and Ikeda, Y.: Fundamental study on river bed deformation near the changing point of river width, Proceedings of Annual Meeting of Kanto branch, JSCE, Vol. 32-2, pp. 111-112, 2005.

4) Kenmochi, H., Tamura, H., Tanaka, H., Kayaba, Y. and Hayashi, T.: A study on the riverbed fluctuation after straightening of the Satetsu River, Report of Riverfront Japan Research Institute, Vol. 15, pp. 96-101, 2004.

5) Shimizu, Y., Fujita, M. and Hirano, M.: Calculation of flow and bed deformation in compound channel with a series of vertical drop spillways, Annual Journal of Hydraulic Engineering, JSCE, Vol. 43, pp. 683-688. 1999.

6) Yamashita, S., Shimizu, Y. and Watanabe, Y.: A study of bed variation at fall in rapid flow river, Annual Journal of Hydraulic Engineering, JSCE, Vol. 35, pp. 35-42, 1991.

7) Japanese Geotechnical Society: Geotechnical Terms Glossary, 1985.

8) Civil Engineering Research Institute for Cold Region: Peaty Soft Ground Countermeasure Manual, 2010.

9) Inoue, T., Shimizu, Y., Parker, G., Yamaguchi, S. and Itou, A.: Influence of sediment supply on bedrock erosional morphology, Journal of Japan Society of Civil Engineers, Ser. B1 (Hydraulic Engineering), Vol. 70, No. 4, pp. 1039-1044, 2014.

10) Nishimori, K. and Sekine, M.: Erosional rate formula of cohesive sediment, Journal of Japan Society of Civil Engineers, Ser. B, Vol. 65, No. 2, pp. 127-140, 2009.

11) Tanaka, G. and Izumi, N.: The bedload transport rate and hydraulic resistance in bedrock channels partly covered with gravel, Journal of Japan Society of Civil Engineers, Ser. B1 (Hydraulic Engineering), Vol. 69, No. 4, pp. 1033-1038, 2013.

12) Sekine, M., Nishimori, K., Fujio, K. and Katagiri, Y.: On erosion process of cohesive sediment and erosion rate formula, Annual Journal of Hydraulic Engineering, JSCE, Vol. 47, pp. 541-546, 2003.

13) Iwagaki, Y.: Hydraulic study of critical tractive force, Proceedings of JSCE, No. 41, pp. 1-21, 1956.

14) Inoue, T., Izumi, N., Shimizu, Y. and Parker, G.: Interaction among alluvial cover, bed roughness, and incision rate in purely bedrock and alluvial-bedrock channel, J. Geophys. Res. Earth Surf, Vol. 119, pp. 2123-2146, 2014.

15) Inoue, T., Izumi, N., Yoneyama, M. and Asahi, K.: Experimental study of erosion rate and critical tractive force on soft rocks, Advances in River Engineering, Vol. 17, pp. 77-82, 2011.

16) Parker, G, and Izumi, N.: Purely erosional cyclic and solitary steps created by flow over a cohesive bed, Journal of Fluid Mechanics, Vol. 419, pp. 203-238, 2000.

17) Igarashi, T., Kashiwagi, S. and Iwata, N.: A study on water cycle in the Yubari and other rivers in the low plain, Report of Riverfront Japan Research Institute, Vol. 25, pp. 17-28, 2014.

(Received June 21, 2018) 